\title{
La herencia de la criminología clínica
}

\author{
Gino Ríos Patio
}

\section{RESUMEN}

El autor examina el estado situacional de la criminología clínica en la realidad nacional, como el legado que nos dejó la antigua escuela positivista italiana que tuvo en Cesare Lombroso su máximo exponente. Asimismo, analiza su proyección en la actual búsqueda de causas de la criminalidad, frente al postulado de otras escuelas criminológicas, en especial de la criminología crítica, que han abandonado (superado) el paradigma etiológico. El objetivo del artículo es evaluar si en la actualidad criminológica tiene vigencia la escuela clínica. El autor concluye, principalmente, en que para la criminología crítica no resulta funcional el enfoque clínico para explicar las causas del crimen y que, no obstante ello, no es conveniente, aun en la actualidad, hacer depender el enfoque criminológico de una sola escuela, teoría o corriente criminológica, pues dependerá del objeto de estudio o de conocimiento, que son el crimen, el criminal, la víctima y el control social.

Palabras clave: Criminología clínica; paradigma etiológico; criminología crítica; paradigma científico.

\section{The inheritance of clinical criminology}

\section{ABSTRACT}

The author examines the situation of clinical criminology in the Peruvian reality, as the legacy left by the old Italian Positivist School of which Cesare Lombroso was its greatest exponent. Moreover, he analyzes its projection in the present search for causes of criminality against postulates of other schools of criminology, especially critical criminology, which have abandoned (overcome) the etiological paradigm. The objective of the article is to evaluate if clinical school is currently valid in criminology. The author mainly concludes that the clinical approach is not functional for critical criminology to explain the causes of crime, and that, nevertheless, even today it is not convenient for the criminological approach to rely on a single school, theory or current of criminology, since it will depend on the object of study or knowledge, which are the crime, criminal, victim and social control.

Keywords: Clinical criminology; etiological paradigm; critical criminology; scientific paradigm.

1. Director del Instituto de Investigación Jurídica de la USMP.

a. Doctor en Derecho, Doctor en Educación, Maestro en Ciencias Penales, Abogado.

b. Diplomado en Filosofía Política por la Universidad de Harvard.

c. Diplomado en Derechos Económicos, Sociales y Culturales y Derecho a la Educación por la Universidad de Ginebra. 


\section{INTRODUCCIÓN}

La búsqueda de las causas de la criminalidad, que constituye la finalidad de la criminología, es un verdadero problema nacional, en primer lugar porque dicha ciencia social no está extendida en su desarrollo investigativo ni en su praxis en la política pública; y en segundo lugar por cuanto no existe voluntad académica ni política para explorar e indagar acerca de la etiología de la conducta criminal, tan solo existe un carácter represivo y retributivo del mal que causa un comportamiento ilícito dañoso, sin que interese prevenir dichas conductas para reducirlas estadísticamente, sino únicamente sancionar algunas de ellas, las perpetradas por individuos pertenecientes a los grupos sociales más desfavorecidos y carenciados.

Por otro lado, la ciudadanía está acostumbrada, por efecto del discurso político y la influencia de los mass media, a convivir con la criminalidad, asumiendo como cierto que el criminal es un ser patológico, enfermo y monstruoso, sin que le importe conocer las causas de dicho comportamiento criminal.

De ahí, precisamente, que los objetivos del presente artículo sean, en primer término, concienciar al lector respecto a la necesidad de conocer las causas o factores criminógenos para mejor proveer a la comprensión de la cuestión criminal $y$, por ende, contribuir a su solución razonable, en términos de prevención, reducción y control. En segundo lugar, examinar lo que nos dice la ciencia médica sobre dichos factores o causas; si la explicación galena puede explicar suficientemente el comportamiento criminal, si existen condiciones biológicas, endocrinológicas o psíquicas determinantes para la conducta criminal o si solo son influyentes; o, por el contrario, si la criminología clínica ha perdido vigencia en el contexto actual de la criminología crítica.

En ese sentido, el trabajo investigativo se justifica porque siendo los fines esenciales del estado el bienestar general y la seguridad integral, la existencia de índices alarmantes de criminalidad en el país, que acusan tendencias de crecimiento, amenaza el orden social, la gobernabilidad del estado y la unidad de la nación.

La línea de desarrollo del trabajo de investigación presenta un capítulo destinado a la criminología clínica, con la finalidad de dar a conocer su ámbito, sentido y alcances con los que se inició en la historia de la criminología; otro capítulo que muestra el estado actual de la criminología clínica en el país; y finalmente la proyección e influencia que se considera tiene en la actualidad esta disciplina frente a un paradigma criminológico contemporáneo diferente al biológico, como es el paradigma científico. Posteriormente se exhiben las conclusiones y recomendaciones.

\section{La criminología clínica}

La criminología clínica nace como escuela criminológica con el médico y criminólogo italiano Ezechia Marco Lombroso, más conocido con el seudónimo Cesare
Lombroso, representante del positivismo criminológico o Nuova Scuola.

Lombroso sostuvo que las causas físicas y biológicas son las que originan la criminalidad; y que el crimen es producto de tendencias innatas de orden genético, visibles en determinados rasgos fisonómicos de los delincuentes habituales, tales como asimetrías del cráneo, formas de mandíbula, orejas, pómulos, arcos superciliares, entre otros.

Ciertamente, la tendencia positivista de la época, segunda mitad del siglo XIX, de arraigar el discurso científico en la sola descripción de la realidad perceptible sensorialmente, sustrayéndolo de otra consideración, influyó en el pensamiento lombrosiano.

La convicción de Lombroso, C. ${ }^{(1)}$ respecto de las causas biológicas de la criminalidad era tan fuerte que sostenía la idea del desarraigo perenne para los criminales adultos incorregibles o su eliminación física para los que además eran peligrosos. Tal era su terapia del delito.

La idea del desarraigo perenne, actualmente es conocida como la expulsión hacia adentro que hace la sociedad del criminal, relegándolo al ostracismo penitenciario; o del hombre con patología mental que realiza un comportamiento criminal, que es confinado a un sanatorio para enfermos mentales en condiciones similares o peores a las de una cárcel.

Resulta evidente, a la luz de la dogmática penal, que si triunfara semejante postulado médico etiológico acabaría con la noción de culpabilidad e incluso con la de imputabilidad del criminal, por ausencia de responsabilidad, en la medida que estaría pre determinado a obrar en un sentido criminal y sus actos no serían libres. Más aún, este pensamiento lombrosiano sería contrario a considerar como atenuante una causa de orden biológico, precisamente porque dicha causa es la que explicaría la peligrosidad del infractor. He aquí una primera cuestión acerca de la explicación causal de la conducta criminal.

Como se puede apreciar, desde sus orígenes, la criminología clínica pretende explicar el delito a partir del estudio, diagnóstico y tratamiento personalizado del delincuente. Ello supone que el crimen es una conducta anómala, propia de una persona enferma, como apunta Garófalo, R. ${ }^{(2)}$. No puede ser de otra manera, pues el significado etimológico de la palabra clínica proviene del griego kliniké que significa lecho y de kliné que quiere decir cama, acostarse o inclinarse, de la cual deriva la mención a la práctica de atender a los pacientes en la cama.

Por cierto, la criminología clínica apunta a establecer el nivel de peligrosidad social del criminal como resultado de la influencia de la convivencia social en la que transcurre su existencia, sobre su constitución biológica o psíquica, lo cual implica axiomáticamente que conceptúa al ser humano como una unidad biológica, psicológica y social. 
De acuerdo con Rodríguez, L. ${ }^{(3)}$ el trabajo clínico en criminología se basa en el paradigma consensualista, según el cual la sociedad es pacífica; en el paradigma etiológico, por el que debe buscarse la etiología del comportamiento criminal; en el análisis morfológico, funcional, psíquico y biográfico del individuo que delinque.

A partir de dicha base, la criminología clínica sostiene que la conducta del hombre se ve influenciada, y puede tornarse criminal, por el entorno físico y social. En ese sentido, factores tales como la herencia cromosomática, lo congénito y lo constitucional, por ejemplo, puede reaccionar de diversa manera frente a estímulos externos y llegar al comportamiento criminal. Es la llamada criminología del paso al acto, según la cual el inicio de lo criminal reside en el interior del hombre, sea que la ocasión para delinquir no la busque el hombre; sea que la busque (tendencia); sea que lo haga en todo momento (temibilidad); o sea que las circunstancias sociales influyan de manera decisiva (reactivo). Según la criminología clínica, ésta sería la dinámica de la conducta criminal, como respuesta de una persona ante una situación determinada.

De lo anterior desciende que la composición o tipología biológica, física u orgánica de una persona pre dispondría o condicionaría su mayor o menor capacidad criminal, en tanto que su peligrosidad estaría definida por sus peculiaridades físicas, psíquicas y mentales.

Esta dimensión clínica de la criminología permitiría aseverar la existencia de un proceso genético, transmisible por herencia, de tendencias, peligrosidad o reactividad criminal, lo que en la imaginación popular o el lenguaje coloquial se ha venido en denominar el gen asesino, afirmación que representa una discusión entre la criminología clínica y la criminología contemporánea, en sus escuelas sociológicas y, sobre todo, en la escuela de la criminología crítica.

Pavarini, M. ${ }^{(4)}$ se refiere a la patologización del criminal como el fundamento epistemológico de la criminología positivista expresada en términos de la escuela clínica, según la cual, lo diverso debía ser buscado en la naturaleza bio psíquica del individuo, con lo que explicaba la criminalidad en términos ahistóricos y apolíticos, legitimando el aparato represivo por ser la visión de la parte sana del organismo que reaccionaba contra la parte enferma. Se trata, ciertamente, de un modelo de pensamiento destinado a justificar y racionalizar el sistema de control social penal. Sin embargo, al considerar el origen de la desviación en una patología individual, ergo en una biología natural, la criminología clínica no consideró que la desviación no es un elemento intrínseco de la conducta, sino resultado de un constructo social que se le atribuye a determinados individuos.

Un ejemplo de esta atribución selectiva es la opinión de Rospigliosi, $\mathrm{F}^{(5)}$ en la que teniendo como telón de fondo el Caso Odebrecht y apoyándose en otra opinión (Julio Luque. El Comercio 26.3.17) sostiene que algunos pretenden prohibirle a Graña y Montero, la "mejor empresa de ingeniería del Perú" que participe en la reconstrucción, además todas las otras grandes empresas constructoras nacionales han estado asociadas también a los brasileños los últimos años, por lo cual también podrían caer; para añadir que investigar y sancionar es muy necesario pero no destruir más de lo que ya está devastado. Posteriormente, el Presidente del Consejo de Ministros ha oficializado que dicha empresa puede participar .

Aquí, por ejemplo, subyace la idea de que la criminalidad económica de grandes corporaciones interesa menos que la criminalidad callejera o de empresas menores. Sutherland, E. ${ }^{(6)}$ observa la mecánica que facilita la impunidad de los delincuentes de cuello blanco. Y apunta que los grandes procesos de estos delincuentes presentan la apariencia de la singularidad que les otorga el prestigio social del acusado pero en realidad no pueden ser más repetitivos y rituales. Enfatiza señalando que como se creen situados en el centro del mundo confunden su caída con la caída del mundo.

La artificialidad del crimen (y no su naturalidad) y la criminalidad de cuello blanco son explicadas por Gilbert Geis al afirmar que "la preocupación por la utilización del poder para explotar y victimizar a quienes se hallan en las posiciones más desfavorecidas, ha marcado los principales sistemas políticos desde que se tiene constancia histórica escrita" (7). Inclusive para el caso de la criminalidad de cuello blanco, Lombroso, citado por Geis, $\mathrm{G}$, sostuvo que los delincuentes de gran poder, a quienes la sociedad venera como jefes, cuentan con marcas de delincuencia congénita, pero su elevada posición suele impedir el reconocimiento de tal carácter delincuencial, su naturaleza depravada puede revelarse demasiado tarde a expensas de todo el país.

La fijación de Lombroso y de la criminología crítica por la raíz biológica del crimen contrasta no solo con la criminología contemporánea. En efecto, Aristóteles sentenció que "los mayores delitos están causados por el exceso y no por la necesidad" ${ }^{(8)}$. La realidad social nos permite apreciar que todas las conductas criminales son realizadas para lograr algo que desean sus perpetradores, que creen no puede ser logrado sin dificultad dentro de los cánones legales, ante lo cual el poder provee de recursos para infringir la ley más finamente que el ciudadano perteneciente a las clases más desfavorecidas.

La etiología clínica del crimen fue criticada fuertemente por Edwin H. Sutherland en 1939, puesto que las circunstancias de anormalidad, patología y aberración de los delincuentes callejeros no eran las características de los delincuentes de cuello blanco, cometidos por personas que ocupaban posiciones de poder en los mundos de la empresa, la política y las profesiones, que ocupan posiciones elevadas en el sistema social.

\section{Estado actual del Perú}

La presencia de la criminología clínica en el país no existe a nivel preventivo ni de tratamiento. Tampoco hay un desarrollo explicativo causal del crimen a partir de 
sus postulados. En efecto, no hay políticas públicas que se basen en estudios clínicos para determinar las causas de la criminalidad y prevenirla, reducirla y controlarla. Ello porque, en primer lugar, la criminología no tiene un desarrollo académico ni científico en el país, dado que no existe la licenciatura en criminología ni estudios de posgrado multidisciplinarios en la materia; en segundo lugar porque la oferta de conocimientos criminológicos se limita a unos cuantos cursos en la carrera de Derecho en algunas universidades y a otros pocos cursos en algunas maestrías de ciencias penales; y en tercer lugar porque el discurso político y mediático predomina sobre cualquier intento serio de abordar la cuestión criminal más allá de la reacción punitiva y de la consideración de anormalidad y monstruosidad de los crímenes comunes, que son los visibles y cotidianos.

De esta manera, la clínica médica carece de interés en emprender actividades académicas y de investigación para buscar las causas del comportamiento criminal. Hay un retraimiento de la universidad para encarar y plantear alternativas de solución científicas al problema número uno del país y mejorar la realidad nacional en materia de seguridad integral, que obviamente está aparejado al bienestar general. El problema no se limita, pues, a la seguridad ciudadana ni a la respuesta, cada vez más drástica, de carácter penal. El crimen se previene y controla. La sociedad no gana nada castigándolo severamente dejando intactas las causas que lo generan. Es mejor ser duros contra las causas y factores criminógenos que únicamente duros contra el crimen.

En efecto, hay que estudiar científicamente el problema criminal antes de intervenir en la reacción social contra el criminal. Recuérdese que el crimen no solo es un doloroso problema individual, sino fundamentalmente un grave problema comunitario, como lo sostiene García-Pablos de Molina, A. ${ }^{(9)}$, por lo que en el fenómeno criminal deben ser considerados el criminal, la víctima, la comunidad y el estado.

El problema de la determinación de las causas de la criminalidad radica, necesariamente, en la multiplicidad de factores que se presentan en la existencia individual y social del hombre, incluidos los factores políticos, lo cual permite concluir en que cada quien puede llegar a convertirse en criminal de una manera distinta, esto es, por una causa diversa. No es, por tanto, el factor biológico, en cualquiera de sus dimensiones, definitivamente la causa primera o final del comportamiento criminal; de ahí que, en materia de tratamiento, por ejemplo, no debería proponerse una intervención científica que pueda servir política o socialmente para estigmatizar a la persona que delinque con base en sus características biológicas, entre otras, con las consecuencias de segregación y discriminación que ello conlleva, sino que debe enfocarse y contemplar también las circunstancias políticas, sociales y físicas que precisamente actúan como detonantes frente a lo innato o congénito, las cuales se encuentran fuera del individuo, en la comunidad. Pero estas variables de un enfoque clínico de la criminología deberán surgir de un emprendimiento inter, multi y trans disciplinario, precisamente para no fragmentar el crimen como objeto de estudio en función de enfoques parciales que segmentarían el problema de acuerdo con los paradigmas propios de cada ciencia, superando de paso el monismo ideológico. Así, un verdadero tratamiento "resocializador" consistiría, desde una perspectiva clínica, en dotar de recursos al hombre para que pueda enervar o controlar sus tendencias, aminorar su peligrosidad, sublimar su reactividad, en fin para emanciparlo y que tome conciencia de su autonomía crítica en pro de oportunidades sociales.

Desde este punto de vista, la imagen del delincuente nato lombrosiano devendría en una deformación o exageración inadmisible que, por contraste, enseñaría cómo mejorando el entorno físico, social y las condiciones políticas, sí es posible atenuar o extinguir la posibilidad de la acción y reacción de los componentes biológicos de la persona; terminaría con el estigma social del enfermo considerado un ser diferente $y$, por ello, no tolerado socialmente y discriminado irremediablemente.

Ha habido, desde entonces, una revolución "copernicana" de la criminología, pues en tiempos del positivismo criminológico se pensaba y sostenía que la explicación causal del crimen se daba en términos biológicos. Hoy aquella tiene otro eje central.

\section{Proyección e influencia}

¿Hay relación entre las mutaciones y enfermedades corporales, las enfermedades mentales y la criminalidad? ¿Los procesos biológicos, entre los que existen ciertos factores de orden genético, biológico y endocrinológico, influyen en el desarrollo antisocial de una persona? ¿El delincuente es distinto del no delincuente? ¿Hay un factor de diferenciación donde reside el porqué del hecho criminal? ¿El origen de la conducta delictiva debe buscarse en los descubrimientos biológico-genéticos?.

Estos y otros interrogantes es necesario despejar para visualizar la proyección e influencia de la criminología clínica, que hoy es un reducto limitado, fundamentalmente debido al pensamiento criminológico contemporáneo, que encarna la criminología crítica, según la cual, las causas de la criminalidad se encuentran en el proceso de criminalización, esto es, en el poder de definición, asignación y ejecución que es atribución del poder punitivo, el que es ejercido de manera desigual, selectiva y discriminatoria en perjuicio de las personas pertenecientes a los grupos sociales más carenciados y vulnerables de la sociedad, situación que se revela en el índice de crímenes denunciados, perseguidos y sancionados, de carácter común, así como, por contraste, se manifiesta en la invisibilidad de los crímenes económicos, del poder político y de la criminalidad de cuello blanco (profesionales de prestigio y personas de alto poder social).

Hoy es posible afirmar que los criminólogos clínicos han desatendido la idea del delincuente nato, cuyo comportamiento criminal -se sostenía- era producto de una 
deficiente evolución biológica, sin embargo es constatable que continúan sujetos al paradigma etiológico, dejando de considerar los otros espacios donde la conducta criminal se origina y manifiesta, como son, entre otros, la comunidad con su otredad y el estado con el control social que produce crimen y criminales.

Considero que una comunidad es complicada y beligerante no sólo porque sus miembros sean intolerantes, sino porque desde su diseño produce miembros conflictivos. Esta situación socio política constituirá un factor criminógeno o causa del crimen interpersonal, la cual tendrá a su vez una razón que le antecede y trasciende al individuo, que vendría a ser una concausa. En esa línea de pensamiento, si asumimos el conflictualismo de la sociedad y no su consensualismo, debemos aceptar que la violencia estructural es, definitivamente, un dato socio político intrínseco a considerar.

Lo anterior no debe significar, sin embargo, una actitud de desdén criminológico respecto de la corriente clínica. Siempre será necesario discurrir, en ocasiones, por otros caminos científicos. Pero hay que subrayar que para la criminología clínica, como para la criminología positivista tradicional, la reflexión socio política acerca de los factores y causas del comportamiento criminal, se subordina al planteo biológico. En otras palabras, es introducida a la probeta clínica. Preguntémonos entonces se desde dicha posición ipodría explicarse clínicamente crímenes como el narcotráfico, el terrorismo, la trata de personas, entre otros?.

Es un hecho que los crímenes acarrean que la sociedad se proteja, pero mejor aún, la existencia de criminales debe motivar a la búsqueda de las mejores soluciones para identificar las causas por las cuales la persona delinque. Una realidad más concreta que los criminales es la de los crímenes, tanto como lo es la de las enfermedades respecto de los enfermos. En la cuestión criminal, sin embargo, no es posible decir que hay criminales corregibles e incorregibles, como sí lo es respecto a la existencia de enfermos incurables y curables.

Lo que pasa es que la solución históricamente ensayada hasta ahora ha fracasado. La pena, no disminuye la criminalidad. La cárcel no resocializa. A penas más graves, más criminalidad. A más condenas privativas de la libertad, más reincidencia y habitualidad en el crimen. ¿Qué se hizo entonces? Cómo no se "rehabilitaban" los condenados, como las penas no resolvían el problema de la criminalidad, se resolvió entonces aplicar políticas de mano dura contra esos "incorregibles", esos "enfermos", esos "anormales".

Este cambio de dirección, de la disuasión penal y el tratamiento en prisión, para el enfermo "social" (desadaptado), sugeridos por la criminología clínica primigenia, presuponía que la conducta criminal era un hecho, no un proceso que resulta de la interacción de los individuos con el estado, como sostiene la nueva criminología. Bajo esta concepción, la criminología se despoja de la bata médica.

En consonancia con el nuevo panorama criminológico, Peñaloza, P. ${ }^{(10)}$ apunta que la pobreza, la desigualdad y la exclusión social, resultantes del proceso de dominación, son las verdaderas causas del crimen. En plena época de la globalización, el apogeo de la tecnología y el neo liberalismo, que exacerban el yo, lo hacen hipertrofiar en el individualismo narcisista y el egoísmo negador de la alteridad y solidaridad, cabe preguntarnos si hay que abandonar por cansancio la idea de que nada funciona y es necesario volver al estudio de las causas biológicas del delito, a la criminología clínica, como plantea Rodríguez, L. (11). ¿Estamos en la encrucijada del camino?

Considero que mientras que las causas se busquen en la estructura social, podríamos hablar de una etiología social que inquiera y escrute por las causas del crimen fuera del hombre, en su relación con el estado y la comunidad, no en su interior. Una perspectiva diferente, macrológica y no micrológica, de reflector telescópico y no de microscopio, para analizar a la sociedad como objeto y no como medio.

En conclusión, al problema de las causas del crimen, la criminología clínica respondió con las ideas de predisposición biológica en relación con el ambiente, que delineaban el desarrollo de la personalidad y pronosticaba el comportamiento criminal, el mismo que consideraba patológico y merecedor de un tratamiento, porque el criminal (anormal) y el no criminal (normal) eran diferentes.

A la luz de las estructuras de poder político económico, resulta evidente que la perspectiva de la criminología clínica que centra su interés únicamente y focaliza el análisis etiológico en el autor, no resulta funcional para explicar las causas del crimen en la actualidad.

Los problemas de diagnóstico, definición y selección dependen de lo que cada comunidad y el estado entiendan por crimen, por castigo y por control social, lo cual advierte el enfoque criminológico aplicado; y es el eje central del discurso criminológico crítico dirigido contra el ejercicio del poder punitivo, que incluso hacen detonar las enfermedades mentales y orgánicas, así como los trastornos psicológicos que erosionados por condiciones y estímulos negativos que trae consigo el ejercicio del poder punitivo se convierten en factores criminógenos .

Lo anterior no obstante, no es conveniente, aun en la actualidad, hacer depender el enfoque criminológico para abordar la determinación de los problemas de definición, selección y diagnóstico, de una sola escuela, teoría o corriente criminológica. Ninguna de estas debe descartarse a priori, por el contrario deben priorizarse para su aplicación, considerando que la escuela, teoría o corriente de pensamiento criminológico adecuado dependerá del objeto de estudio o de conocimiento, que son el crimen, el criminal, la víctima y el control social. La multi, trans e inter disciplinariedad siempre da buenos resultados porque la realidad no se nos presenta dividida. 
La criminología tiene un carácter holístico, no reduccionista, dinámico, empírico, científico social y político, que le permite buscar en el ámbito natural del hombre, que es el social y político, las causas de su comportamiento criminal en una multiplicidad de fuentes con abordajes propios de la respectiva ciencia aplicada en el proceso indagatorio, cuyos hallazgos son analizados e interpretados con una visión superior unificadora propia de la criminología.

\section{REFERENCIAS BIBLIOGRÁFICAS}

1. Lombroso C. Le più recenti scoperte ed applicazioni della psichiatria ed antropologia criminale. Vol 18: Bocca. 1893

2. Garófalo R. Criminología. Teoría del delito y de la represión. México. Ángel Editor. 1999.

3. Rodríguez L. Criminología clínica, $5^{\circ}$ ed. México: Porrúa. 2012

4. Pavarini M. Control y dominación. Teorías criminológicas burguesas y proyecto hegemónico. Buenos Aires: Siglo XXI Editores. 1983.

5. Rospigliosi F. Un error con nombre propio. El Comercio. 2 de abril de 2017; Sección A:24.

6. Sutherland, E. El delito de cuello blanco. Madrid. Ediciones La Piqueta. 1999.

7. Geis G. El delito de cuello blanco como concepto analítico e ideológico. En: Bueno F, coordinador. Derecho penal y criminología como fundamento de la política criminal. Estudios en homenaje al Prof. A. Serrano Gómez. Madrid: Dykinson;2006. p 309-24

8. Jowett B, Davis H. Aristotle's politics: Clarendon Press.1908
9. De Molina A. Criminologia. Una introducción a sus fundamentos teóricos para juristas. $2^{\text {a }}$ ed. valencia: Tirant lo Blanch.1994.

10. Peñaloza, P. La antigüedad del presente. Defensa del futuro. En: Peñaloza P. coordinador. Narcotráfico, crisis social, derechos humanos y gobernabilidad. Una agenda para el futuro. México: Porrúa; 2010, p. 71-93.

11. Rodríguez L. Criminología clínica contemporánea. En: Ponencia ante el Congreso de Criminología Contemporánea "Profesor Héctor F. González Salinas", Universidad Autónoma de Nuevo León. México; 2009.

Fuentes de financiamiento:

Este artículo ha sido financiado por el autor.

\section{Conflictos de interés:}

El autor declara no tener ningún conflicto de interés.

\section{Correspondencia:}

\section{Gino Ríos Patio}

Dirección: Av. Alameda de la Molina Vieja 695 Dpto. 03. La Molina. Lima, Perú

Teléfono: 997974318

Correo electrónico: griosp@usmp.pe

Recibido: 06 de abril de 2017

Aprobado: 01 de mayo de 2017 